\title{
Preservation characteristics of buffalo semen in citric acid-whey as an extender
}

\author{
M. Bhosrekar and N. C. Ganguli \\ National Dairy Research Institute, Karnal 132001, India
}

It has been reported from this laboratory (Ganguli, Bhosrekar \& Stephen, 1973; Ganguli, 1974) that 'citric acid-whey' (CAW) is a superior diluent for the preservation and freezing of buffalo semen. Data on the preservation characteristics of buffalo semen in this extender are presented in this communication.

Ejaculated semen was collected by means of an artificial vagina (Herman \& Madden, 1953) from 8 Murrah buffalo bulls of the Institute herd. CAW was prepared from the milk of cows of the Red Sindhi, Sahiwal and Tharparkar breeds and cross-bred cows as described previously (Ganguli et al., 1973). The pH of CAW was adjusted to different levels with $10 \% \mathrm{NaOH}$. The skim milk-egg yolk (SKMEY) and sodium bicarbonate-glucose-fructose-egg yolk (SBGFEY) diluents were prepared by the methods given by Tomer \& Desai (1961). Roller-dried and spray-dried milk powder prepared from cow skim milk were from the Experimental Dairy of the Institute. Samples of the semen from each bull were placed in each diluent. The motility of the spermatozoa was evaluated by the method of Salisbury \& VanDemark (1961) and progressive motility was taken as the assessment criterion.

Motility was sustained for a longer period in CAW than in the other two diluents tested (Table 1). Of the breeds tested, CAW prepared from the milk of Red Sindhi cows was observed to be superior, whereas CAW prepared from colostrum was ineffective. An immediate difference in the initial motility was noted when spermatozoa were placed in CAW prepared from milk of different breeds of cow. The $\mathrm{pH}$ was observed to be critical and motility in CAW was greatest at pH6.8. Initial motility was greatest with dilution of semen with CAW at 1:5 (90\%) and 1:10 (83\%), and the drop after storage at $5-7^{\circ} \mathrm{C}$ for $96 \mathrm{hr}$ was only 25 and $28 \%$ respectively. Some improvement in sperm motility after storage was obtained when fructose or glycerol were added to the CAW diluent. CAW prepared from skim milk powder was effective as a buffalo semen extender and roller-dried powder did not even require the heating step necessary for the milk (Thacker \& Almquist; Ganguli et al., 1973)

Table 1. Motility of buffalo spermatozoa in different diluents at $5-7^{\circ} \mathrm{C}$ before and after storage

\begin{tabular}{lccc}
\hline \multirow{2}{*}{ Diluent* } & \multicolumn{3}{c}{$\%$ Motility } \\
\cline { 2 - 4 } & $0 \mathrm{hr}$ & $96 \mathrm{hr}$ & $144 \mathrm{hr}$ \\
\hline CAW & 85.0 & $58 \cdot 0$ & - \\
SKMEY & 78.0 & 43.0 & - \\
SBGFEY & 77.0 & 28.0 & - \\
CAW + fructose (1.0\%) & 75.0 & 60.0 & 40.0 \\
CAW + glycerol (7.0\%) & 82.0 & 62.0 & 50.0 \\
CAW from spray-dried powder & & & \\
$\quad$ Unheated & 69.5 & 12.5 & - \\
$\quad$ Heated & 79.5 & $63 \cdot 2$ & 44.0 \\
CAW from roller-dried powder & & & \\
$\quad$ Unheated & 76.0 & 58.6 & 45.0 \\
Heated & 79.0 & 63.2 & 50.0 \\
CAW from packet & 76.0 & 59.0 & 40.0 \\
\hline
\end{tabular}

* All extenders were adjusted to $\mathrm{pH} 6.8$ and dilution rate was $1: 10$. CAW was always from cow skim milk. In all cases at least 8 experiments were carried out. 
and spray-dried powder based diluents. A packet containing skim-milk powder and citric acid (solid) has been formulated for the easy preparation of CAW for field application and semen diluent made in this way gave good results (Table 1).

To test the efficacy of the diluents, buffalo cows were artificially inseminated as described by Herman \& Madden (1953). The conception rate in fresh semen in CAW (at pH 6.8, 1:10 dilution with addition of antibiotics) was $63.4 \%$ (260 inseminations) compared with $44.8 \%$ (58 inseminations) with semen in SBGFEY $(P<0.05)$, when the cows were inseminated on the first day of oestrus (detected by running with a teaser bull). After storage of semen in CAW for $24 \mathrm{hr}$, the conception rate was $6.5 \%$ higher.

We are indebted to Dr D. Sundaresan, Director of the National Dairy Research Institute, Karnal, for his continued encouragement in this project, and to $\mathrm{Mr} \mathrm{O}$. P. Tandon and Dr J. Stephen, for their help. This paper is N.D.R.I. Publication No. 75-201.

\section{References}

GANGULI, N.C. (1974) A breakthrough in artificial insemination of buffalo. Indian Dairyman 26, 243247.

Ganguli, N.C., Bhosrekar, M. \& Stephen, J. (1973) Milk whey as a diluent for buffalo semen. J. Reprod. Fert. 35, 355-358.

Herman, H.A. \& Madden, F.W. (1953) The Artificial Insemination of Dairy Cattle. A Handbook and Laboratory Manual. Lucas Brothers, Columbia.
Salisbury, G.W. \& VANDemark, N.L. (1961) Physiology of Reproduction and Artificial Insemination of Cattle. Freeman \& Co., London.

ThaCKer, I.L. \& AlmQuist, J.O. (1951) Milk and milk products as dilutors for bovine semen. J. Anim. Sci. $10,1082$.

TOMER, N.S. \& DESAI, R.N. (1961) A comparative study of various dilutors for preservation of buffalo semen at 5 to $7^{\circ} \mathrm{C}$. II. Skim milk containing dilutors. Indian J. Dairy Sci. 14, 61-66. 